\title{
Prenatal Exposure to Maternal Cigarette Smoking and the Adolescent Cerebral Cortex
}

\author{
Roberto Toro', Gabriel Leonard ${ }^{2}$, Jacqueline V Lerner ${ }^{3}$, Richard M Lerner ${ }^{4}$, Michel Perron ${ }^{5,6}$, G Bruce Pike $^{2}$, \\ Louis Richer ${ }^{7}$, Suzanne Veillette ${ }^{5,6}$, Zdenka Pausova ${ }^{1,6}$ and Tomáš Paus*,1,2 \\ 'Brain and Body Centre, University of Nottingham, Nottingham, UK; ${ }^{2}$ Montreal Neurological Institute, McGill University, Montreal, QC, Canada; \\ ${ }^{3}$ Department of Counseling and Applied Developmental Psychology, Boston College, Boston, MA, USA; ${ }^{4}$ Child Development Department, Tufts \\ University, Medford, MA, USA; ${ }^{5}$ CEGEP Jonquiere, Jonquiere, QC, Canada; ${ }^{6}$ University of Montreal, Montreal, QC, Canada; ${ }^{7}$ University of Quebec \\ in Chicoutimi, Chicoutimi, QC, Canada
}

Smoking during pregnancy is associated with long-term consequences on offspring behavior. We measured thickness of the cerebral cortex using magnetic resonance images obtained in 155 adolescents exposed in utero to maternal smoking and compared them with I59 non-exposed subjects matched by maternal education. Orbitofrontal, middle frontal, and parahippocampal cortices were thinner in exposed, as compared with non-exposed, individuals; these differences were more pronounced in female adolescents. In exposed females, the thickness of the orbitofrontal cortex correlated negatively with a self-rated assessment of caring, one of the components of a model of positive youth development. These findings provide evidence of the long-term impact of prenatal environment on a neural substrate of cognition and social behavior.

Neuropsychopharmacology (2008) 33, I019-1027; doi: I 0. I038/sj.npp. I 301484; published online 4 July 2007

Keywords: nicotine; pregnancy; adolescence; cerebral cortex; positive youth development

\section{INTRODUCTION}

Prevalence of cigarette smoking during pregnancy is still high; it varies considerably (10-50\% of pregnant women) across different countries and socioeconomic groups. In the United States, the average prevalence of cigarette smoking during pregnancy was $16.3 \%$ in 1984 and decreased to $11.8 \%$ in 1996 (Ebrahim et al, 2000). In the United Kingdom, maternal cigarette smoking during pregnancy is more common, $24 \%$ in 1995 (Statistics on Smoking, 2000). In Canada, $23.7 \%$ of mothers included in the National Longitudinal Study of Children and Youth reported smoking cigarettes during pregnancy in 2002 (Connor and McIntyre, 2002). The strongest predictor of smoking both before and during pregnancy is a woman's socioeconomic status (SES); for example, a prospective study of 589 preadolescent children found that, in $2000,52 \%$ of their low-SES mothers smoked cigarettes during pregnancy (Cornelius et al, 2000). Similar relationships were observed in the Saguenay Lac Saint-Jean (SLSJ) region of Quebec, Canada; we found that prevalence of tobacco use is negatively correlated with the level of schooling and with

*Correspondence: Dr T Paus, Brain and Body Centre, University of Nottingham, University Park, Nottingham, NG7 2RD, UK, Tel: + 44 II5 95।5362, Fax: + 44 II5 8468274,

E-mail: tomas.paus@nottingham.ac.uk

Received 16 March 2007; revised 17 May 2007; accepted 18 May 2007 household income (Institut de la statistique du Québec, 2001). The following rates of cigarette smoking in women were found: $39.0 \%$ women with the lowest level of education (1st quintile) vs $23.6 \%$ of women with the highest level of education (5th quintile); $47.2 \%$ of women with the lowest income $v s 27.4 \%$ of women with the highest income.

Cigarette smoke inhaled by a pregnant woman affects the fetus in a number of ways, including the direct pharmacological effects of nicotine and the other chemicals it contains, hypoxia associated with increased levels of carboxyhemoglobin, as well as nicotine-induced constriction of the uteroplacental vessels and the associated decrease in the flow of oxygen and nutrients from the mother to the fetus (Lambers and Clark, 1996; Grassi et al, 2000).

Given the multiplicity of such adverse effects on the fetus, it is not surprising that prenatal exposure to maternal cigarette smoking (PEMCS) is associated with negative cognitive and behavioral outcomes. In a prospective cohort study, Fried and colleagues (Fried, 1995) observed systematic differences between children born to 'heavy smokers' ( $>20$ cigarettes/day) and to non-smoking mothers, in several cognitive domains, including processing of auditory stimuli, attention, and language comprehension. Other (Olds et al, 1994; Lassen and Oei, 1998; Obel et al, 1998) but not all (MacArthur et al, 2001) investigators have observed similar effects. Furthermore, a recent study in adolescent smokers described deficits in visuospatial 
memory that was greater in individuals exposed to maternal cigarette smoking prenatally, as compared with nonexposed adolescents (Jacobsen et al, 2006). Several studies also revealed an increased incidence of externalizing disorders in general (Breslau and Chilcoat, 2000), and attention-deficit hyperactivity (Milberger et al, 1998) and conduct (Wakschlag et al, 1997; Weissman et al, 1999) disorders in particular. Some studies also observed an association between PEMCS and criminal behavior in adulthood (Brennan et al, 1999; Räsänen et al, 1999), and higher rates of aggression in children and adults (Orlebeke et al, 1999; Räsänen et al, 1999). Finally, PEMCS may increase the probability of experimenting with cigarette smoking in childhood (Cornelius et al, 2000) and of developing cigarette smoking addiction in adolescence (Kandel et al, 1994; Kandel and Udry, 1999; Weissman et al, 1999; Buka et al, 2003).

The effect of PEMCS on the human brain is largely unknown. A recent study examined group differences in task-related brain activity, measured with functional magnetic resonance imaging (fMRI) in adolescent smokers with and without the history of PEMCS during the performance of attentional tasks; combined current (smokers) and prenatal exposure was associated with higher fMRI signal in several cortical regions involved in auditory attention (Jacobsen et al, 2007). At a receptor level, another study reported subtle differences in the expression of nicotinic and muscarinic acetylcholine receptors in the brains of 5- to 12-week-old foetuses exposed and nonexposed to maternal cigarette smoking (Falk et al, 2005). Indirect evidence suggests detrimental effects of PEMCS on brain growth and development. Kallen (2000) analyzed the Swedish Medical Birth Registry (1983-1996: 1362169 infants) and found significant negative correlation between PEMCS and head circumference at birth. Neuroanatomical studies carried out in experimental animals exposed prenatally to nicotine showed nicotine-induced acute and chronic changes in cholinergic, catecholaminergic, and other neurotransmitter systems (Lichtensteiger et al, 1988; Slotkin, 1998, 2004). In terms of brain structure, Roy and Sabherwal $(1994,1998)$ observed a significant reduction in brain weight, cortical thickness in the somatosensory cortex, neural density in layer $\mathrm{V}$ of the somatosensory cortex, and the neural area of the dentate gyrus, CA1, and CA3 regions of the hippocampus. Using a whole-embryo culture Roy et al (1998) were able to demonstrate a direct effect of nicotine on neuroepithelium; they found evidence of cytoplasmic vacuolation, enlargement of intercellular spaces, and an increased incidence of apoptotic cells. The above effects may be mediated by the direct effect of nicotine on cell proliferation, survival, and migration (Levitt, 1998; Slotkin, 1998). As pointed out by Levitt (1998), 'the convergence of neurotransmitter, growth factor and hormone activity on similar intracellular signalling systems suggests the potential for significant interactions among molecular components that regulate [neural] development'.

As pointed out above, PEMCS is associated with a number of negative behavioral outcomes, some of which are believed to be a part and parcel of the so-called antisocial behavior (van Goozen et al, 2007; Connor et al, 2006). Current theories of youth development emphasize that positive or healthy psychological and social functioning does not involve only the absence of risk/problem behaviors, but also include the presence of characteristics of successful and adaptive behavior. In the 'positive youth development' (PYD) perspective (Lerner, 2005), the presence of psychosocially and physically healthy change is indexed not by decreases in negative behaviors (eg substance use and abuse, bullying, or depression) but by increases in attributes indicative of thriving, such as the 'five Cs' of PYD: Competence, Confidence, Connection, Character, and Caring (Lerner et al, 2000, 2005; Eccles and Gootman, 2002; Roth and Brooks-Gunn, 2003). These 'Cs' have been found to be the outcomes of functionally and developmentally appropriate (adaptive) interactions between the young person and his/her social ecology; importantly, these attributes appear to be inversely related to indicators of both internalizing and externalizing risk/ problem behaviors (Gestsdottir and Lerner, 2007). Given both the early findings of associations between PEMCS and antisocial behavior, and the current theoretical and empirical emphases in the study of youth development, it is important to assess links between PEMCS and the presence of indicators of positive development among adolescents.

Here we report findings obtained in the Saguenay Youth Study, a large-scale project investigating effects of PEMCS on brain and behavior in adolescent offspring (Pausova et al, 2007). The Saguenay Youth Study is a retrospective study of long-term consequences of PEMCS in which multiple quantitative phenotypes are acquired over four sessions (home, hospital, laboratory, and school). To facilitate the search for genes that modify an individual's response to PEMCS, the study is family based (adolescent sibships) and is carried out in a relatively geographically isolated population of the SLSJ region in Quebec, Canada. DNA is acquired in both biological parents and in adolescent siblings.

\section{SUBJECTS AND METHODS}

All participants were recruited in the context of an ongoing study of the effects of PEMCS on brain and behavior, and cardiovascular and metabolic health in adolescence: the Saguenay Youth Study. The Saguenay Youth Study is a retrospective study of long-term consequences of PEMCS in which multiple quantitative phenotypes are acquired over five sessions (telephone interview, home, hospital, laboratory, and school). The study is family based (adolescent sibships) and is carried out in a relatively geographically isolated population inhabiting the SLSJ region in Quebec, Canada. The Research Ethics Committee of the Chicoutimi Hospital approved the study protocol.

\section{Ascertainment}

Details of the recruitment and testing procedures are provided in Pausova et al (2007). Briefly, subjects were recruited in secondary schools in the SLSJ region. The recruitment begins with the team visiting all classrooms in a given school and presenting the study to the students. Concurrently, an information brochure, a letter from the 
principal, and a consent form for a telephone interview are mailed to the parents. Subsequently, a research nurse conducts a telephone interview with interested families (usually with the child's mother) to verify their eligibility. Additional information is acquired using a medical questionnaire completed by the child's biological parent. The main exclusion criteria for both exposed and non-exposed adolescents are: (1) positive history of alcohol abuse during pregnancy; (2) positive medical history for meningitis, malignancy, and heart disease requiring heart surgery; (3) severe mental illness (eg autism, schizophrenia) or mental retardation (IQ <70); and (4) MRI contraindications. The following selection criteria are used for both exposed and non-exposed subjects: (1) age 12-18 years; (2) one or more siblings in the same age group; and (3) maternal and paternal grand-parents of French-Canadian ancestry. Exposed subjects must have positive history of maternal cigarette smoking ( $>1$ cigarette/day in the 2 nd trimester of pregnancy). The non-exposed subjects are matched to the exposed ones based on the level of maternal education and the school attended. In the case of mothers of non-exposed offspring, we require negative history of maternal cigarette smoking during pregnancy and during the 12-month period preceding the pregnancy. Cigarette smoking before and during pregnancy is ascertained by a research nurse during a structured telephone interview with the mother; this information is verified in the majority of subjects using medical records from the time of pregnancy.

\section{Assessment of General Intelligence and PYD}

We used the Wechsler Intelligence Scale for Children to assess general intelligence. This assessment was carried out at the beginning of a 6-h neuropsychological battery. The PYD was assessed with a questionnaire based on the 'five Cs' model: Competence, Confidence, Character, social Connection, and Caring or compassion (Lerner et al, 2005). The questionnaire contains over 300 questions, which are answered by the adolescent. To calculate the score for each of the five scales (ie five Cs), all individual items were first rescaled on a 0 -to-12 point scale. Overall, the scoring is such that a high score indicates more positive behavior on each of the 'five C's' scale. The average of the five scales represents the PYD score. Scores for PYD have been found to be inversely related to the scores for depression indexed by the Center for Epidemiological Studies Depression measure (Radloff, 1977), both within a given grade level (eg fifth grade; Lerner et al, 2005) and across grades (from 5 th grade to 6 th grade; Gestsdottir and Lerner, 2007; Jelicic et al, 2007). Similarly, in these same reports, scores for PYD are inversely related to indices of smoking, bullying, and drug use (Lerner et al, 2005; Gestsdottir and Lerner, 2007; Jelicic et al, 2007).

\section{MRI}

MRI data were collected on a Phillips 1.0-T superconducting magnet. High-resolution anatomical T1-weighted (T1W) images were acquired using the following parameters: 3D RF-spoiled gradient echo scan with 140-160 sagittal slices, $1-\mathrm{mm}$ isotropic resolution, $\mathrm{TR}=25 \mathrm{~ms}, \mathrm{TE}=5 \mathrm{~ms}$, and flip angle $=30^{\circ}$. We measured cortical thickness using Free-
Surfer, a set of automated tools for reconstruction of the brain cortical surface (Fischl and Dale, 2000). For every subject, FreeSurfer segments the cerebral cortex, the white matter, and other subcortical structures, and then computes triangular meshes that recover the geometry and the topology of the pial surface and the gray/white interface of the left and right hemispheres. The local cortical thickness is measured based on the difference between the position of equivalent vertices in the pial and gray/white surfaces. A correspondence between the cortical surfaces across the subjects is established using a nonlinear alignment of the principal sulci in each subject's brain with an average brain (Fischl et al, 1999). To take into account the multiple local comparisons performed, we estimated statistical significance of group differences in cortical thickness using the false-discovery rate method (Genovese et al, 2000). While the MRI data in this study were collected at a slightly lower magnetic field strength than typically used in morphometric studies (1 Tesla $v s$ 1.5 Tesla), the signal-to-noise ratio (SNR) and gray matter-white matter (GM-WM) contrast-to-noise ratio were excellent and the data had minimal intensity non-uniformity effects thereby producing robust tissue classifications. We compared the SNR and GM-WM contrast-to-noise ratios (CNR) in T1W images acquired at $1 \mathrm{~T}$ (Philips scanner used in this study) and at 1.5T (Philips scanner located at the Brain \& Body Centre at the University of Nottingham). We found very similar mean SNRs: 25.6 at $1.5 \mathrm{~T}$ and 25.8 at $1 \mathrm{~T}$. More importantly, the GM-WM CNRs were also similar: 5.8 at $1.5 \mathrm{~T}$ and 5.7 at $1 \mathrm{~T}$.

Statistical analyses of cortical thickness were performed in two ways: (1) mean values were obtained for each of 33 cortical regions segmented automatically in each subject based on the nonlinear transformation of the subject's surface reconstructions into an average cortical surface; and (2) thickness values were also determined at each of 163842 vertices representing the subject's cortical surface. Given the known age-related decrease in cortical thickness during childhood and adolescence (Shaw et al, 2006; Sowell et al, 2004), and observed in this sample, we used age as a covariate in both types of analyses.

\section{RESULTS}

Table 1 describes the final sample of 314 adolescents in whom we were able to compute cortical thickness reliably. Note that there are no significant differences across the four subgroups (ie 'exposed' and 'non-exposed' male and female adolescents) in the number of subjects, their age, family income, and full-scale intelligence quotient. Female subjects are more advanced than males in their sexual maturation as indicated by the Tanner pubertal stage (Petersen et al, 1988); the exposed and non-exposed subjects of the same sex do not differ in this respect. The number of cigarettes smoked during pregnancy by the mothers of the exposed subjects is identical in the male and female subgroups. As expected, the birth weight of exposed adolescents was lower than that of the non-exposed subjects in both genders (males: $\mathrm{F}(1,147)=11.7, p=0.001$; female: $\mathrm{F}(1,161)=15.9$, $p<0.0001$; Table 1). 
Table I Characterization of Adolescent Males and Females Non-exposed and Exposed In Utero to Maternal Cigarette Smoking

\begin{tabular}{|c|c|c|c|c|}
\hline & \multicolumn{2}{|c|}{ Males } & \multicolumn{2}{|c|}{ Females } \\
\hline & Non-exposed & Exposed & Non-exposed & Exposed \\
\hline Age (days) & $5530 \pm 649$ & $5645 \pm 721$ & $5527 \pm 781$ & $5633 \pm 697$ \\
\hline Puberty (Tanner) stage & $3.6 \pm 0.9$ & $3.5 \pm 0.9$ & $4.1 \pm 0.8$ & $4.3 \pm 0.7$ \\
\hline Birth weight (g) & $3573 \pm 480$ & $3307 \pm 463$ & $3468 \pm 469$ & $3142 \pm 494$ \\
\hline Full scale IQ & $104 \pm 12$ & $106 \pm 14$ & $105 \pm 11$ & $104 \pm 13$ \\
\hline
\end{tabular}

In the region-based analysis, we found significant differences between the exposed and non-exposed subjects in several cortical regions, including the lateral orbitofrontal and middle frontal cortex, as well as the parahippocampal cortex; except for the parahippocampal cortex, these differences were significant only in the female sample (Table 2). In all cases, the cortex was thinner in the exposed $v s$ non-exposed adolescents. The vertex-based analysis confirmed these findings; we observed significant (false discover rate (FDR) threshold $F=12.8, p=0.05$, corrected) cortical thinning at the vertices constituting the left lateral orbitofrontal cortex (OFC) in female adolescents (Figure 1; female: $\mathrm{F}(3,163)=18.9, \quad p<0.0001 \quad$ (uncorrected); male: $\mathrm{F}(3,149)=9.4, p=0.003$ (uncorrected); sex by exposure interaction: $\mathrm{F}(5,313)=0.9, p=0.3)$.

As pointed out above, the summary score of PYD, as measured by our instrument, can be conceptualized as an index of the overall adaptive regulation of person-context relations. We found significantly lower scores of PYD in the exposed as compared with non-exposed subjects but only in the female adolescents $(F(1,157)=19.2, p<0.0001)$. The effect of PEMCS on each PYD component was significant for all PYD components (except confidence), where the exposed females scored lower than non-exposed ones on Competence $(\mathrm{F}(1,156)=14.0, p=0.0003)$, Character $(\mathrm{F}(1,157)=10.8, \quad p=0.001)$, Connection $(\mathrm{F}(1,157)=10.1$, $p=0.002)$, and Caring $(\mathrm{F}(1,156)=7.2, p=0.01)$. No significant differences were found between the exposed and non-exposed male adolescents in any of the PYD components.

Given the observed effect of PEMCS on the thickness of the OFC and its known role in social behavior (Raine et al, 2000; Adolphs, 2001; Seguin, 2004), we examined the possible relationship between this brain measure and the Caring score in each of the four subgroups (ie exposed and non-exposed male and female adolescents). We observed significant negative correlation between the two measures in exposed females only (left OFC: $\mathrm{F}(1,76)=7.5, p=0.008$; right $\mathrm{OFC}: \mathrm{F}(1,77)=3.8, p=0.06) ; \mathrm{F}<1.0$ in all other groups); in this group, thickness of the left OFC explained $9 \%$ of the variance in Caring.

\section{DISCUSSION}

Our findings revealed a significant albeit moderate impact of PEMCS on brain structure and function, namely on the thickness of several cortical regions and on several measures of PYD. Surprisingly, these effects were significant mainly in female adolescents. Furthermore, thickness of the OFC explained some of the inter-individual differences in Caring. The latter was the case only in the exposed females, thus suggesting a shared mechanism mediating this structure-function relationship. Before discussing putative exposure-related mechanisms underlying the above findings, we wish to examine possible contributions of factors that may be related to maternal smoking during pregnancy only indirectly.

As pointed out above, we minimized differences between the exposed and non-exposed subjects vis-à-vis their SES; they did not differ in household income or in the education level of their parents. Nonetheless, we did observe several differences between the exposed and non-exposed samples in factors that might influence the child's brain and social behavior during postnatal development. Two such factors stand out in this context. First, mothers who smoked during pregnancy were less likely to breastfeed (Pausova et al, 2007); maternal behavior associated with breastfeeding may influence social behavior of the offspring (Fergusson and Woodward, 1999). Second, using self-reports, we found slightly higher incidence of antisocial behavior during the adolescence of the (smoking) mothers of exposed adolescents, as compared with the (non-smoking) mothers of nonexposed subjects. But when we included the above two factors in our model evaluating the effect of exposure on brain structure and PYD, or on their inter-relationship, we found no contribution of these two variables.

The exposure status and the number of cigarettes smoked during each pregnancy rely on information provided by the mother during the telephone interview. For all subjects born in the two main hospitals in the region (Chicoutimi and Jonquiere), we have verified the mother's report by extracting relevant antenatal information from the medical chart completed during pregnancy (1st trimester, 2nd trimester, and 3rd trimester). We were able to obtain relevant information in a total of 260 adolescents $(87 \%$ of all subjects born in Chicoutimi and Jonquiere), with an equal distribution across the exposed and non-exposed adolescents. To assess the overall agreement between the exposure status ascertained antenatal from the medical records and by the maternal report during the telephone interview, we calculated $\kappa$-statistics (range: -1 to +1 ) and found that, with a value of $0.69 \pm 0.04$, it indicates a 'good' strength of agreement (Landis and Koch, 1977; good agreement: $>0.6$ to $\leqslant 0.8$ ). 
Table 2 Effect Size (Cohen's $d$ ) and Statistical Significance (F-ratio, p-value) of Differences in Cortical Thickness between Exposed and Non-exposed Subjects

\begin{tabular}{|c|c|c|c|c|c|c|c|c|c|c|c|c|}
\hline \multirow{2}{*}{ Region } & \multicolumn{6}{|c|}{ Male } & \multicolumn{6}{|c|}{ Female } \\
\hline & \multicolumn{3}{|c|}{ Left } & \multicolumn{3}{|c|}{ Right } & \multicolumn{3}{|c|}{ Left } & \multicolumn{3}{|c|}{ Right } \\
\hline \multicolumn{13}{|l|}{ Frontal lobe } \\
\hline Caudal middle frontal & -0.07 & 0.01 & 0.94 & -0.09 & 0.02 & 0.9 & -0.32 & 3.37 & 0.07 & -0.38 & 5.07 & 0.03 \\
\hline Frontal pole & 0.03 & 0.23 & 0.63 & 0 & 0.08 & 0.77 & -0.22 & 1.72 & 0.19 & 0.05 & 0.19 & 0.66 \\
\hline Medial orbito frontal & 0.25 & 3.42 & 0.07 & -0.24 & 1.93 & 0.17 & -0.21 & 1.24 & 0.27 & -0.02 & 0.02 & 0.88 \\
\hline Para central & 0 & 0.26 & 0.61 & -0.23 & 0.77 & 0.38 & -0.09 & 0.11 & 0.74 & -0.32 & 3.42 & 0.07 \\
\hline Pars opercularis & -0.05 & 0.01 & 0.91 & -0.02 & 0.01 & 0.91 & -0.14 & 0.43 & 0.51 & -0.1 & 0.15 & 0.7 \\
\hline Pre central & -0.05 & 0 & 0.99 & 0.05 & 0.36 & 0.55 & -0.24 & 2.25 & 0.14 & -0.28 & 2.77 & 0.1 \\
\hline Rostral anterior cingulate & -0.24 & 1.81 & 0.18 & -0.26 & 2.52 & 0.11 & -0.08 & 0.1 & 0.75 & 0.09 & 0.54 & 0.46 \\
\hline Rostral middle frontal & 0.01 & 0.48 & 0.49 & -0.08 & 0 & 0.97 & -0.43 & 6.65 & 0.01 & -0.31 & 3.13 & 0.79 \\
\hline Superior frontal & -0.03 & 0.09 & 0.75 & -0.14 & 0.21 & 0.65 & -0.23 & 1.55 & 0.21 & -0.18 & 0.86 & 0.35 \\
\hline \multicolumn{13}{|l|}{ Parietal lobe } \\
\hline Inferior parietal & 0.2 & 3.96 & 0.05 & 0.16 & 2.19 & 0.14 & -0.11 & 0.16 & 0.69 & -0.15 & 0.53 & 0.47 \\
\hline Isthmus cingulate & 0.06 & 0.38 & 0.54 & -0.01 & 0.11 & 0.74 & -0.11 & 0.19 & 0.66 & -0.19 & 0.86 & 0.36 \\
\hline Post central & 0.06 & 0.55 & 0.46 & 0 & 0.23 & 0.63 & -0.08 & 0.11 & 0.74 & -0.13 & 0.38 & 0.54 \\
\hline Pre cuneus & 0.13 & 2.27 & 0.13 & 0.27 & 5.72 & 0.02 & -0.21 & 1.07 & 0.3 & -0.32 & 3.38 & 0.07 \\
\hline Inferior temporal & 0.03 & 0.2 & 0.66 & 0.03 & 0.22 & 0.64 & 0.02 & 0.03 & 0.86 & -0.11 & 0.39 & 0.53 \\
\hline Middle temporal & -0.25 & 1.49 & 0.22 & -0.06 & 0.03 & 0.87 & -0.2 & 1.28 & 0.26 & -0.01 & 0.01 & 0.94 \\
\hline Parahippocampal & -0.33 & 3.39 & 0.07 & -0.44 & 6.91 & 0.01 & -0.24 & 2.32 & 0.13 & -0.44 & 8.02 & 0.005 \\
\hline Superior temporal & -0.06 & 0.01 & 0.92 & -0.11 & 0.12 & 0.73 & -0.27 & 2.49 & 0.12 & -0.21 & 1.29 & 0.26 \\
\hline Temporal pole & -0.23 & 2.19 & 0.14 & -0.24 & 2.55 & 0.11 & -0.02 & 0.95 & 0.76 & -0.18 & 1.84 & 0.18 \\
\hline Transverse temporal & 0.05 & 0.28 & 0.6 & -0.34 & 3.55 & 0.06 & -0.31 & 3.38 & 0.07 & -0.39 & 5.23 & 0.02 \\
\hline \multicolumn{13}{|l|}{ Occipital lobe } \\
\hline Cuneus & 0.02 & 0.16 & 0.69 & 0.13 & 1.74 & 0.2 & -0.26 & 2.33 & 0.13 & -0.14 & 0.45 & 0.51 \\
\hline Lateral occipital & 0 & 0.1 & 0.76 & 0.03 & 0.33 & 0.57 & 0.06 & 0.27 & 0.6 & 0.06 & 0.24 & 0.63 \\
\hline Lingual & -0.02 & 0 & 0.98 & -0.04 & 0.02 & 0.88 & -0.21 & 1.3 & 0.26 & -0.21 & 1.4 & 0.24 \\
\hline Peri calcarine & 0.28 & 3.35 & 0.07 & 0.07 & 0.75 & 0.39 & 0.07 & 0.53 & 0.47 & 0.14 & 1.09 & 0.3 \\
\hline
\end{tabular}

The most striking finding revealed by our study is the apparently higher sensitivity to PEMCS of the female $v s$ male adolescents vis-à-vis the PYD and the thickness of the OFC. Note, however, that the sex by exposure interactions was not significant. Overall, the size of the PEMCS effect (Cohen's $d$ ) on cortical thickness (Table 2) was lower in male, as compared with female, adolescents; power calculations indicate that this is unlikely to be due to a slightly lower number of male $v s$ female subjects. This observation may simply reflect greater overall sensitivity of the female fetus to PEMCS. In a large epidemiological study (1 815310 singleton births), PEMCS was associated with a greater 


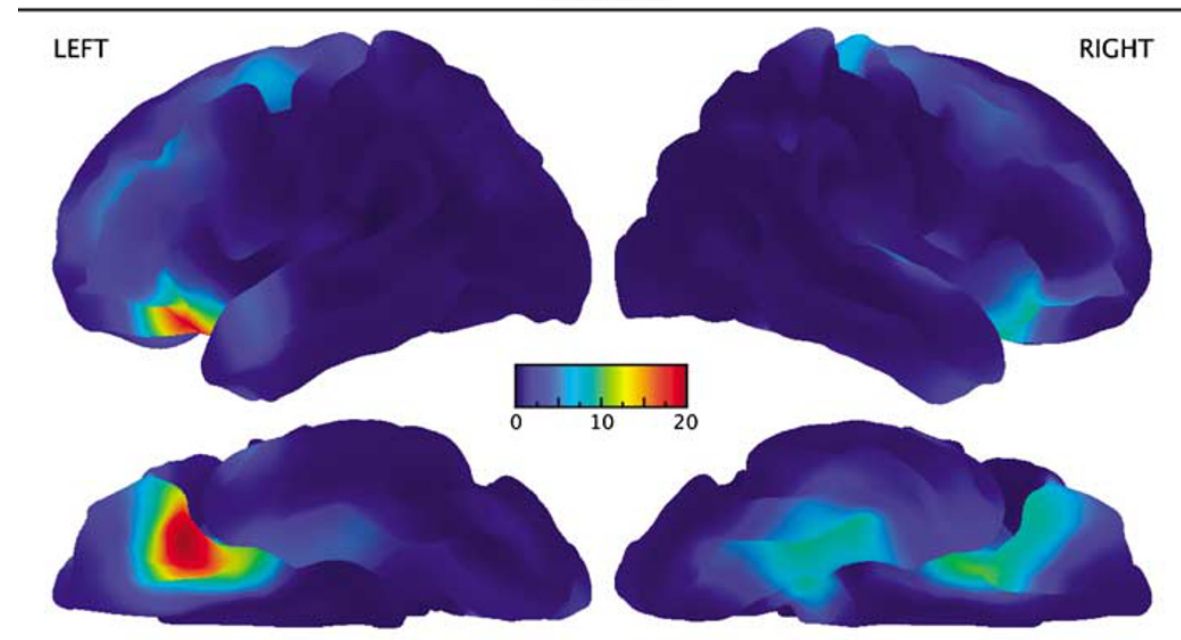

MALES

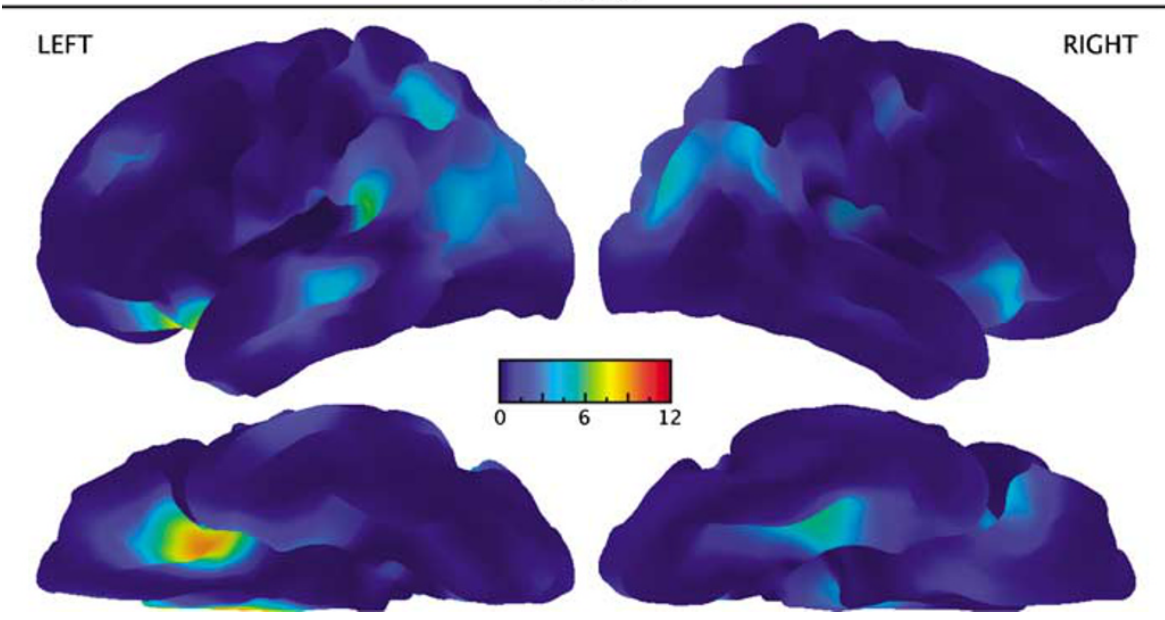

Figure I Surface maps of statistical significance of PEMCS on cortical thickness. The F-ratio of the exposure effect in female (upper half) and male (lower half) adolescents is color coded and projected over an average lateral (top) and ventral (bottom) cortical surface. Given the false-discovery rate threshold of $F=12.8, p=0.05$ (corrected), differences in cortical thickness between the exposed and non-exposed groups are significant only in female adolescents.

negative impact on birth weight in newborn girls than in boys (Voigt et al, 2006); in our sample, the size of the PEMCS effect on birth weight is also somewhat larger in the female (Cohen's $d=0.70)$ than in male subjects $(d=0.57)$. At the same time, it is also possible that the presumably greater sensitivity to PEMCS is specific to certain behaviors and their neural substrate. At a behavioral level, sex-specific effects have been observed in some, but not all, studies of PEMCS effects on the initiation of smoking during adolescence (Kandel et al, 1994; Niaura et al, 2001; Oncken et al, 2004; Munafo et al, 2006) and on the incidence of conduct disorder in childhood (Maughan et al, 2001; Wakschlag and Hans, 2002). In experimental animals, sexspecific effects of prenatal exposure to nicotine include the presence of an attentional deficit or lack of habituation in open field observed in female but not male rats (Popke et al, 1997; Romero and Chen, 2004). In the rat brain, most of the previous work focused on the effects of prenatal exposure to nicotine on various neurotransmitter systems (Slotkin, 1998; Slikker et al, 2005), and a number of sex-specific effects have been described. Thus, prenatal exposure to nicotine reduces the number of bindings sites for the serotonin transporter in the rat cerebral cortex; this effect persists through adolescence into adulthood and appears stronger in female (11\% decrease) than in male $(6 \%)$ rats (Xu et al, 2001). At a receptor level, exposure to prenatal nicotine increases the number of $5 \mathrm{HT} 1 \mathrm{~A}$ receptors in the cerebral cortex of males but not females, and decreases the number of receptors in the striatum of females but not males (Slotkin et al, 2006). These are but two examples of sex-specific effects of prenatal exposure to nicotine that may translate into long-lasting morphological changes in serotonin-rich regions. One such region is the OFC (Tork, 1990; Dillon et al, 1991; Marutle et al, 2001; Tauscher et al, 2001) and this is where we found significant effects of PEMCS on cortical thickness in the female adolescents.

In general, thickness of a cortical region, as estimated from MRI, most likely reflects the volume of various cellular compartments constituting the cortex (axons (29\%), dendrites (30\%), cell bodies and vessels (14\%), and glia (10\%) percentages based on the mouse cerebral cortex) and the effect of the adjacent white matter (Braitenberg, 2001; 
Paus, 2005). A number of neurotransmitter systems are affected by prenatal exposure to nicotine (Slotkin, 2004; Slotkin et al, 2006). Neurotransmitters, such as serotonin or acetylcholine, may affect the number of cellular elements in the cortex during both prenatal and postnatal periods (Levitt et al, 1997; Levitt, 1998; Herlenius and Lagercrantz, 2001; Luo et al, 2003; van Kesteren and Spencer, 2003). We speculate that the observed 'thinning' of the OFC in the female adolescents exposed in utero to maternal cigarette smoking may reflect nicotine-induced downregulation of the serotoninergic and/or cholinergic systems with subsequent decrease in activity-triggered neuronal (eg dendrites) and glial growth. As shown in the rat studies, it is likely that such a nicotine-induced dysregulation of a neurotransmitter system can persist beyond the fetal period and could therefore modify maturational changes taking place during childhood and adolescence. It is also important to note that the human OFC (Brodmann areas 10 and 11) ranks, together with other prefrontal cortical regions (Brodmann areas 32, 46, 9 and 47), among the top 10 (out of 41) brain regions vis-à-vis the concentration of nicotinic receptors, as assessed with autoradiography using epibatidine as the ligand (Karl Zilles, personal communication). The relatively high concentration of nicotinic receptors in the prefrontal cortex is consistent with the observed effects of PEMCS in the orbitorfrontal and middle prefrontal cortex.

Overall, our findings provide evidence of the effects of PEMCS on the thickness of human cerebral cortex. These effects appear to be limited to a few regions in the frontal and temporal cortex and are more pronounced in female adolescents. The concomitant effects of PEMCS on PYD is again only observed in the female adolescents, and underlie the seriousness of the neurodevelopmental consequences of this particular form of in utero adversity. The effects were of moderate size at a group level. Future studies in this and similar cohorts, as well as in experimental animals, may uncover the role of genetic factors that either protect or sensitize an individual to the prenatal exposure to harmful substances such as cigarette smoke.

\section{ACKNOWLEDGEMENTS}

The Saguenay Youth Study project is funded by the Canadian Institutes of Health Research (TP, ZP), Heart and Stroke Foundation of Quebec (ZP), and the Canadian Foundation for Innovation (ZP). We thank the following individuals for their contributions in designing the protocol, acquiring, and analysing the data: MR team (Dr Michel Bérubé, Sylvie Masson, Suzanne Castonguay, Julien Grandisson, Marie-Josée Morin), cardio nurses (Jessica Blackburn, Mélanie Gagné, Jeannine Landry, Catherine Lavoie, Lisa Pageau, Réjean Savard, France Tremblay, Jacynthe Tremblay), psychometricians (Chantale Belleau, Mélanie Drolet, Catherine Harvey, Stéphane Jean, Hélène Simard, Mélanie Tremblay), ÉCOBES team (Nadine Arbour, Julie Auclair, Marie-Ėve Blackburn, Marie-Ève Bouchard, Annie Houde, Catherine Lavoie, Dr Luc Laberge), nutritionists (Caroline Benoit and Henriette Langlais), laboratory technicians (Denise Morin and Nadia Mior), Julie Bérubé, Celine Bourdon, Rosanne Aleong, Dr Jennifer Barrett, Candice Cartier, Dale Einarson, Helena Jelicic, and Valerie Legge.
We thank Dr Jean Mathieu for medical follow-ups. Finally, we thank Drs Peter Fried and Ted Slotkin for helpful discussions on the effects of prenatal exposure to maternal cigarette smoking/prenatal nicotine on brain and behavior.

\section{DISCLOSURE/CONFLICT OF INTEREST}

The authors declare that, except for income received from their primary employers, no financial support or compensation has been received from any individual or corporate entity over the past 3 years for research or professional service and there are no financial holdings that could be perceived as constituting a potential conflict of interest.

\section{REFERENCES}

Adolphs R (2001). The neurobiology of social cognition. Curr Opin Neurobiol 11: 231-239.

Braitenberg V (2001). Brain size and number of neurons: an exercise in synthetic neuroanatomy. J Comput Neurosci 10: 71-77.

Brennan PA, Grekin ER, Mednick SA (1999). Maternal smoking during pregnancy and adult male criminal outcomes. Arch Gen Psychiatry 56: 215-219.

Breslau N, Chilcoat HD (2000). Psychiatric sequelae of low birth weight at 11 years of age. Biol Psychiatry 47: 1005-1011.

Buka SL, Shenassa ED, Niaura R (2003). Elevated risk of tobacco dependence among offspring of mothers who smoked during pregnancy: a 30-year prospective study. Am J Psychiatry 160: 1978-1984.

Connor DF, Carlson GA, Chang KD, Daniolos PT, Ferziger R, Findling RL et al (2006). Stanford/Howard/AACAP Workgroup on Juvenile Impulsivity and Aggression. Juvenile maladaptive aggression: a review of prevention, treatment, and service configuration and a proposed research agenda. J Clin Psychiatry 67: $808-820$.

Connor SK, McIntyre L (2002). In: Willms JD (ed). Vulnerable Children: Findings from Canada's National Longitudinal Survey of Children and Youth. University of Alberta Press: Edmonton, AB, Canada. pp 131-145.

Cornelius MD, Leech SL, Goldschmidt L, Day NL (2000). Prenatal tobacco exposure: is it a risk factor for early tobacco experimentation? Nicotine Tob Res 2: 45-52.

Dillon KA, Gross-Isseroff R, Israeli M, Biegon A (1991). Autoradiographic analysis of serotonin 5-HT1A receptor binding in the human brain postmortem: effects of age and alcohol. Brain Res 554: 56-64.

Ebrahim SH, Floyd RL, Merritt II RK, Decoufle P, Holtzman D (2000). Trends in pregnancy-related smoking rates in the United States, 1987-1996. JAMA 283: 361-366.

Eccles J, Gootman JA (eds) (2002). Community Programs to Promote Youth Development. National Academy Press: Washington, DC.

Falk L, Nordberg A, Seiger A, Kjaeldgaard A, Hellstrom-Lindahl E (2005). Smoking during early pregnancy affects the expression pattern of both nicotinic and muscarinic acetylcholine receptors in human first trimester brainstem and cerebellum. Neuroscience 132: 389-397.

Fergusson DM, Woodward LJ (1999). Breast feeding and later psychosocial adjustment. Paediatr Perinat Epidemiol 13: 144-157.

Fischl B, Dale AM (2000). Measuring the thickness of the human cerebral cortex from magnetic resonance images. Proc Natl Acad Sci USA 97: 11050-11055. 
Fischl B, Sereno MI, Tootell RB, Dale AM (1999). High-resolution intersubject averaging and a coordinate system for the cortical surface. Hum Brain Mapp 8: 272-284.

Fried PA (1995). Prenatal exposure to marihuana and tobacco during infancy, early and middle childhood: effects and an attempt at synthesis. Arch Toxicol Suppl 17: 233-260.

Genovese CR, Lazar NA, Nichols T (2000). Thresholding of statistical maps in functional neuroimaging using the false discovery rate. Neuroimage 15: 870-878.

Gestsdottir S, Lerner RM (2007). Intentional self-regulation and positive youth development in early adolescence: findings from the 4-H Study of Positive Youth Development. Dev Psychol 43: 508-521.

Grassi G, Seravalle G, Magnoni M, Mancia G (2000). Effects of cigarette smoking on systemic hemodynamics. Contrib Nephrol 130: $21-30$.

Herlenius E, Lagercrantz H (2001). Neurotransmitters and neuromodulators during early human development. Early Hum Dev 65: 21-37.

Institut de la statistique du Québec (2001). L'enquête sociale et de santé 1998. Division Santé Québec, Collection la santé et le bien-être. Publications du Québec: Sainte-Foy. pp 642.

Jacobsen LK, Slotkin TA, Mencl WE, Frost SJ, Pugh KR (2007). Gender-specific effects of prenatal and adolescent exposure to tobacco smoke on auditory and visual attention. Neuropsychopharmacology.

Jacobsen LK, Slotkin TA, Westerveld M, Mencl WE, Pugh KR (2006). Visuospatial memory deficits emerging during nicotine withdrawal in adolescents with prenatal exposure to active maternal smoking. Neuropsychopharmacology 31: $1550-1561$.

Jelicic H, Bobek D, Phelps E, Lerner JV, Lerner RM (2007). Using positive youth development to predict contribution and risk behaviors in early adolescence: findings from the first two waves of the 4-H Study of Positive Youth Development. Int J Behav Dev 31: 263-273.

Kallen K (2000). Maternal smoking during pregnancy and infant head circumference at birth. Early Hum Dev 58: 197-204.

Kandel DB, Udry JR (1999). Prenatal effects of maternal smoking on daughters' smoking: nicotine or testosterone exposure? Am J Public Health 89: 1377-1383.

Kandel DB, Wu P, Davies M (1994). Maternal smoking during pregnancy and smoking by adolescent daughters. Am J Public Health 84: 1407-1413.

Landis JR, Koch GG (1977). The measurement of observer agreement for categorical data. Biometrics 33: 159-174.

Lambers DC, Clark KE (1996). The maternal and fetal physiologic effects of nicotine. Semin Perinatol 20: 115-126.

Lassen K, Oei TP (1998). Effects of maternal cigarette smoking during pregnancy on long-term physical and cognitive parameters of child development. Addict Behav 23: 635-653.

Lerner RM (2005). Promoting Positive Youth Development: Theoretical and Empirical Bases. White paper prepared for the Workshop on the Science of Adolescent Health and Development, National Research Council/Institute of Medicine. National Academies of Science: Washington, DC.

Lerner RM, Fisher CB, Weinberg RA (2000). Toward a science for and of the people: promoting civil society through the application of developmental science. Child Dev 71: 11-20.

Lerner RM, Lerner JV, Almerigi J, Theokas C, Phelps E, Gestdotir S et al (2005). Positive youth development, participation in community youth development programs, and community contributions of fifth-grade adolescents: findings from the First Wave of the 4-H Study of Positive Youth Development. J Early Adolesc 25: 17-71.

Levitt P (1998). Prenatal effects of drugs of abuse on brain development. Drug Alcohol Depend 51: 109-125.
Levitt P, Harvey JA, Friedman E, Simansky K, Murphy EH (1997). New evidence for neurotransmitter influences on brain development. Trends Neurosci 20: 269-274.

Lichtensteiger W, Ribary U, Schlumpf M, Odermatt B, Widmer HR (1988). Prenatal adverse effects of nicotine on the developing brain. Prog Brain Res 73: 137-157.

Luo X, Persico AM, Lauder JM (2003). Serotonergic regulation of somatosensory cortical development: lessons from genetic mouse models. Dev Neurosci 25: 173-183.

MacArthur C, Knox EG, Lancashire RJ (2001). Effects at age nine of maternal smoking in pregnancy: experimental and observational findings. BJOG 108: 67-73.

Marutle A, Zhang X, Court J, Piggott M, Johnson M, Perry R et al (2001). Laminar distribution of nicotinic receptor subtypes in cortical regions in schizophrenia. J Chemical Neuroanatomy 22: $115-126$.

Maughan B, Taylor C, Taylor A, Butler N, Bynner J (2001). Pregnancy smoking and childhood conduct problems: a causal association? J Child Psychol Psychiat 42: 1021-1028.

Milberger S, Biederman J, Faraone SV, Jones J (1998). Further evidence of an association between maternal smoking during pregnancy and attention deficit hyperactivity disorder: findings from a high-risk sample of siblings. J Clin Child Psychol 27: 352-358.

Munafo MR, Wileyto EP, Murphy MF, Collins BN (2006). Maternal smoking during late pregnancy and offspring smoking behaviour. Addict Behav 31: 1670-1682.

Niaura R, Bock B, Lloyd EE, Brown R, Lipsitt LP, Buka S (2001). Maternal transmission of nicotine dependence: psychiatric, neurocognitive and prenatal factors. Am J Addict 10: 16-29.

Obel C, Henriksen TB, Hedegaard M, Secher NJ, Ostergaard J (1998). Smoking during pregnancy and babbling abilities of the 8-month-old infant. Paediatr Perinat Epidemiol 12: 37-48.

Olds DL, Henderson Jr CR, Tatelbaum R (1994). Intellectual impairment in children of women who smoke cigarettes during pregnancy. Pediatrics 93: 221-227.

Oncken C, McKee S, Krishnan-Sarin S, O'Malley S, Mazure C (2004). Gender effects of reported in utero tobacco exposure on smoking initiation, progression and nicotine dependence in adult offspring. Nicotine Tob Res 6: 829-833.

Orlebeke JF, Knol DL, Verhulst FC (1999). Child behavior problems increased by maternal smoking during pregnancy. Arch of Environ Health 54: 15-19.

Paus T (2005). Mapping brain maturation and cognitive development during adolescence. Trends Cogn Sci 9: 60-68.

Pausova Z, Paus T, Abrahamowicz M, Almerigi J, Arbour N, Bernard $M$ et al (2007). Genes, maternal smoking and the offspring brain and body during adolescence: design of The Saguenay Youth Study. Human Brain Mapping 28: 502-518.

Petersen AC, Crockett L, Richards M, Boxer A (1988). A self-report measure of pubertal status: reliability, validity, and initial norms. $J$ Youth Adoles 17: 117-133.

Popke EJ, Tizabi Y, Rahman MA, Nespor SM, Grunberg NE (1997). Prenatal exposure to nicotine: effects on prepulse inhibition and central nicotinic receptors. Pharmacol Biochem Behav 58: 843-849.

Radloff LS (1977). The CES-D scale: a self-report depression scale for research in the general population. Appl Psychol Meas 1: 385-401.

Raine A, Lencz T, Bihrle S, LaCasse L, Colletti P (2000). Reduced prefrontal gray matter volume and reduced autonomic activity in antisocial personality disorder. Arch Gen Psychiat 57: 119-127.

Rasanen P, Hakko $H$, Isohanni M, Hodgins S, Jarvelin MR, Tiihonen J (1999). Maternal smoking during pregnancy and risk of criminal behavior among adult male offspring in the Northern Finland 1966 Birth Cohort. Am J Psychiatry 156: 857-862. 
Romero RD, Chen WJ (2004). Gender-related response in openfield activity following developmental nicotine exposure in rats. Pharmacol Biochem Behav 78: 675-681.

Roth JL, Brooks-Gunn J (2003). What exactly is a youth development program? Answers from research and practice. Appl Dev Sci 7: 94-111.

Roy TS, Andrews JE, Seidler FJ, Slotkin TA (1998). Nicotine evokes cell death in embryonic rat brain during neurulation. $J$ Pharmacol Exp Ther 287: 1136-1144.

Roy TS, Sabherwal U (1994). Effects of prenatal nicotine exposure on the morphogenesis of somatosensory cortex. Neurotoxicol Teratol 16: 411-421.

Roy TS, Sabherwal U (1998). Effects of gestational nicotine exposure on hippocampal morphology. Neurotoxicol Teratol 20: $465-473$.

Seguin JR (2004). Neurocognitive elements of antisocial behavior: relevance of an orbitofrontal cortex account. Brain Cogn 55: 185-197.

Shaw P, Greenstein D, Lerch J, Clasen L, Lenroot R, Gogtay N et al (2006). Intellectual ability and cortical development in children and adolescents. Nature 440: 676-679.

Slikker Jr W, Xu ZA, Levin ED, Slotkin TA (2005). Mode of action: disruption of brain cell replication, second messenger, and neurotransmitter systems during development leading to cognitive dysfunction-developmental neurotoxicity of nicotine. Crit Rev Toxicol 35: 703-711.

Slotkin J (1998). Fetal nicotine or cocaine exposure: which one is worse? Pharmacol Exp Ther 285: 931-945.

Slotkin TA (2004). Cholinergic systems in brain development and disruption by neurotoxicants: nicotine, environmental tobacco smoke, organophosphates. Toxicol Appl Pharmacol 198: 132-151.

Slotkin TA, Tate CA, Cousins MM, Seidler FJ (2006). Prenatal nicotine exposure alters the responses to subsequent nicotine administration and withdrawal in adolescence: serotonin receptors and cell signaling. Neuropsychopharmacology 31: 2462-2475.
Sowell ER, Thompson PM, Leonard CM, Welcome SE, Kan E, Toga AW (2004). Longitudinal mapping of cortical thickness and brain growth in normal children. J Neurosci 24: 8223-8231.

Statistics on smoking (2000). England, 1978 onwards. Statistical Bulletin 2000/17. National Statistics, Department of Health: United Kingdom.

Tauscher J, Verhoeff NP, Christensen BK, Hussey D, Meyer JH, Kecojevic A et al (2001). Serotonin 5-HT1A receptor binding potential declines with age as measured by [11C]WAY-100635 and PET. Neuropsychopharmacology 24: 522-530.

Tork I (1990). Anatomy of the serotonergic system. Ann NY Acad Sci 600: 9-34.

van Goozen SH, Fairchild G, Snoek H, Harold GT (2007). The evidence for a neurobiological model of childhood antisocial behavior. Psychol Bull 133: 149-182.

Van Kesteren RE, Spencer GE (2003). The role of neurotransmitters in neurite outgrowth and synapse formation. Rev Neurosci 14: $217-231$

Voigt M, Hermanussen M, Wittwer-Backofen U, Fusch C, Hesse V (2006). Sex-specific differences in birth weight due to maternal smoking during pregnancy. Eur J Pediatr 165: 757-761.

Wakschlag LS, Hans SL (2002). Maternal smoking during pregnancy and conduct problems in high-risk youth: a developmental framework. Dev Psychopathol 14: 351-369.

Wakschlag LS, Lahey BB, Loeber R, Green SM, Gordon RA, Leventhal BL (1997). Maternal smoking during pregnancy and the risk of conduct disorder in boys. Arch Gen Psychiatry 54: 670-676.

Weissman MM, Warner V, Wickramaratne PJ, Kandel DB (1999). Maternal smoking during pregnancy and psychopathology in offspring followed to adulthood. I Am Acad Child Adolesc Psychiatry 38: 892-899.

Xu Z, Seidler FJ, Ali SF, Slikker Jr W, Slotkin TA (2001). Fetal and adolescent nicotine administration: effects on CNS serotonergic systems. Brain Res 914: 166-178. 